\section{Iraq crisis spursnew bioweapons moves}

\section{David Dickson}

Lack of provision in the Biological Weapons Convention for monitoring and verifying compliance has long been a worry. But negotiations for such provision have been given new momentum by recent events in Iraq.

[LONDON] The recent crisis over Iraq seems to have b oosted efforts to reach int ernational agreement on ways to monitor the spread of biological weapons.

Those seeking to curb the spread of such weapons have long criticized the lack of any provision in the Biological Weapons Convention (BWC) of 1972 for monitoring and verifying the compliance of signatory states. Negotiations have been taking place since 1995 on a protocol to the BWC designed to achieve just this.

But until now, efforts to implement a verification regime had been held back by those countries - in particular the United States - that have claimed verification to be impractical, and a potential threat to both national security and the commercial confidentiality of their pharmaceutical and biotechnology industries.

Late last month, however, in his State of the Union address, President Bill Clinton spoke of his keenness to see negotiations on the protocol speeded up. In particular, he indicated for the first time that the United States is prepared to accept the concept of on-site inspection of both declared and undeclared sites.

In reaching this decision, Clinton has opened the way for detailed discussion between Western allies of the type of biological weapons verification regime that they would like to see introduced. "We are not yet at the beginning of the end [of negotiations]; but in a sense, this is the end of the beginning," says one diplomat.

No direct link has been made to concern about reports of stocks of anthrax and other agents held by Saddam Hussein. But there is a widespread impression that the critical situation in Iraq has been an important catalyst for the US decision by placing the issue of biological weapons at the top of the political agenda.

Until recently, for example, it was being said in Washington that strong opposition to any form of on-site monitoring from the pharmaceutical and biotechnology industries, supported by their allies in Congress, was likely to block any further progress.

But Clinton's statement, and subsequent explanatory information released by the White House, indicate that, at least as far as the administration is concerned, the voice of international prudence has received the support of the 'higher echelons' in a tense interagency negotiation.

Several major obstacles remain to agreement on a protocol. The pharmaceutical industry, for example, is said to have already indicated its uneasiness with the Clinton administration's position.

Perhaps even harder to persuade, some observers think, will be the defence establishment, including some of those working on biological weapons defence in the national weapons laboratories, who remain deeply concerned at the prospect of opening themselves up to international inspection.

And the United States still has to reach a common position with its Western allies, let alone other major powers. Indeed, even European states have yet to reach agreement on what a protocol should contain (although the chances of this being achieved relatively soon are said to be high, given that the United Kingdom - long an ardent advocate of a president of the European Union).

One example of the gap between the United States and the United Kingdom is the question of the decision-making procedure strict verification regime - is currently the
[LONDON] Academics

concerned with arms control are floating preliminary proposals for a treaty that

international crime for any individual to help a state to develop biological weapons. The treaty would apply, for example, to a researcher coming to the state from a foreign country.

One of the loopholes of the current anti-biological weapons regime is that legal sanctions are left to individual signatory states. This can create a major problem if such a state - Iraq was forced to ratify after the Gulf War in 1991 - proves reluctant to act against those suspected of would make it an

that should be adopted for so-called 'challenge' inspections. Britain is keen to adopt a 'red light' process as already exists for the Chemical Weapons Convention. Using this process, if a country is suspected of violating the convention, an inspection could automatically take place unless blocked by a certain number of countries.

The Clinton administration, however, has said it prefers an alternative, 'green light' approach, requiring a minimum number of countries to vote for an inspection. This position would be more difficult politically to achieve - and is thought by some to have been introduced as a concession to opponents of on-site inspections.

Further details of the US position are likely to be clarified at a high-level meeting next month between the administration and the pharmaceutical industry. In parallel, US diplomats will be meeting other Western countries in an attempt to forge a common position they can present to the Ad Hoc Group that has been working since last summer on the draft text of a protocol.

Although Clinton said in his speech that he would like to see negotiations on the protocol completed by the end of the year, this is widely seen as optimistic. Indeed, some are concerned that, having suddenly decided to stop dragging its feet, the United States now runs a different risk, of upsetting other countries by attempts to impose its own formula for a protocol on the negotiations.

But even those with reservations about the details of the US position say the chances of agreeing a protocol detailing an international verification regime on biological weapons have markedly improved. If the Iraq crisis turns out to have had any silver lining, it may be that.

David Dickson

\title{
Individuals face weapons work indictment
}

being engaged in biological

weapons work

The proposal for a new international treaty, which would enable other states to indict such individuals if found on their territory, has been drafted by a group of researchers at Harvard University in the United States and the University of Sussex in the United Kingdom.

"O ur idea is to try to find a means to hold individuals responsible," says Matthew Meselson, professor of natural sciences at Harvard and a long-time campaigner against chemical and biological weapons. "These could be heads of state, or they could be the so-called 'evil professors' willing to help another country develop biological weapons."

Meselson points out that there are several significant precedents for making such activity an international crime, such as the already agreed outlawing of aircraft hijacking and theft of nuclear materials.

Many details would have to be negotiated among potential signatories. A key point, for example, is deciding which court would have ultimate jurisdiction.

But a draft of a possible convention has already been drawn up and is scheduled for eventual submission to the United Nations General Assembly. D.D. 